
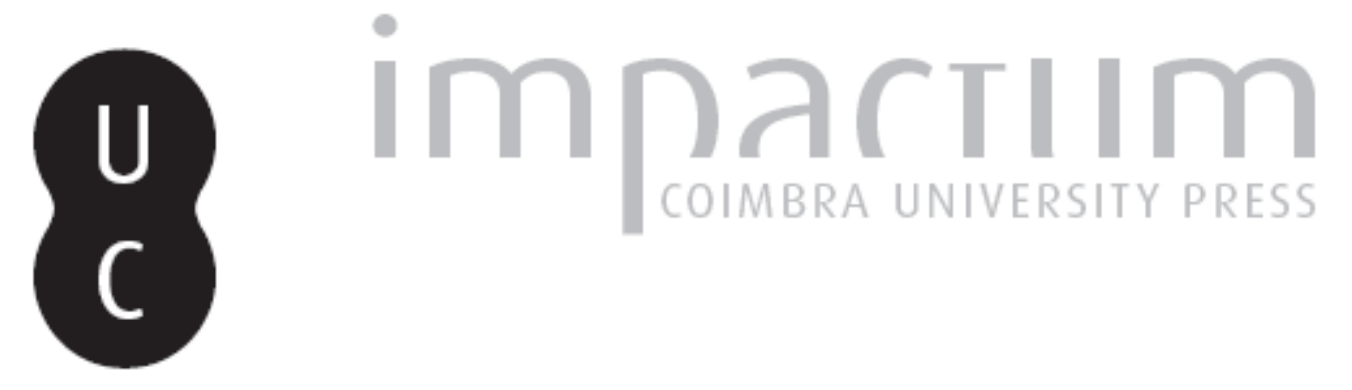

\title{
Cidade Universitária de Coimbra: património e exaltação
}

Autor(es): Rosmaninho, Nuno

Publicado por: Imprensa da Universidade de Coimbra

URL persistente:

URI:http://hdl.handle.net/10316.2/35447

DOI:

DOI:http://dx.doi.org/10.14195/0870-4147_45_26

Accessed : $\quad$ 26-Apr-2023 12:24:08

A navegação consulta e descarregamento dos títulos inseridos nas Bibliotecas Digitais UC Digitalis, UC Pombalina e UC Impactum, pressupõem a aceitação plena e sem reservas dos Termos e Condições de Uso destas Bibliotecas Digitais, disponíveis em https://digitalis.uc.pt/pt-pt/termos.

Conforme exposto nos referidos Termos e Condições de Uso, o descarregamento de títulos de acesso restrito requer uma licença válida de autorização devendo o utilizador aceder ao(s) documento(s) a partir de um endereço de IP da instituição detentora da supramencionada licença.

Ao utilizador é apenas permitido o descarregamento para uso pessoal, pelo que o emprego do(s) título(s) descarregado(s) para outro fim, designadamente comercial, carece de autorização do respetivo autor ou editor da obra.

Na medida em que todas as obras da UC Digitalis se encontram protegidas pelo Código do Direito de Autor e Direitos Conexos e demais legislação aplicável, toda a cópia, parcial ou total, deste documento, nos casos em que é legalmente admitida, deverá conter ou fazer-se acompanhar por este aviso.

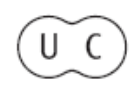




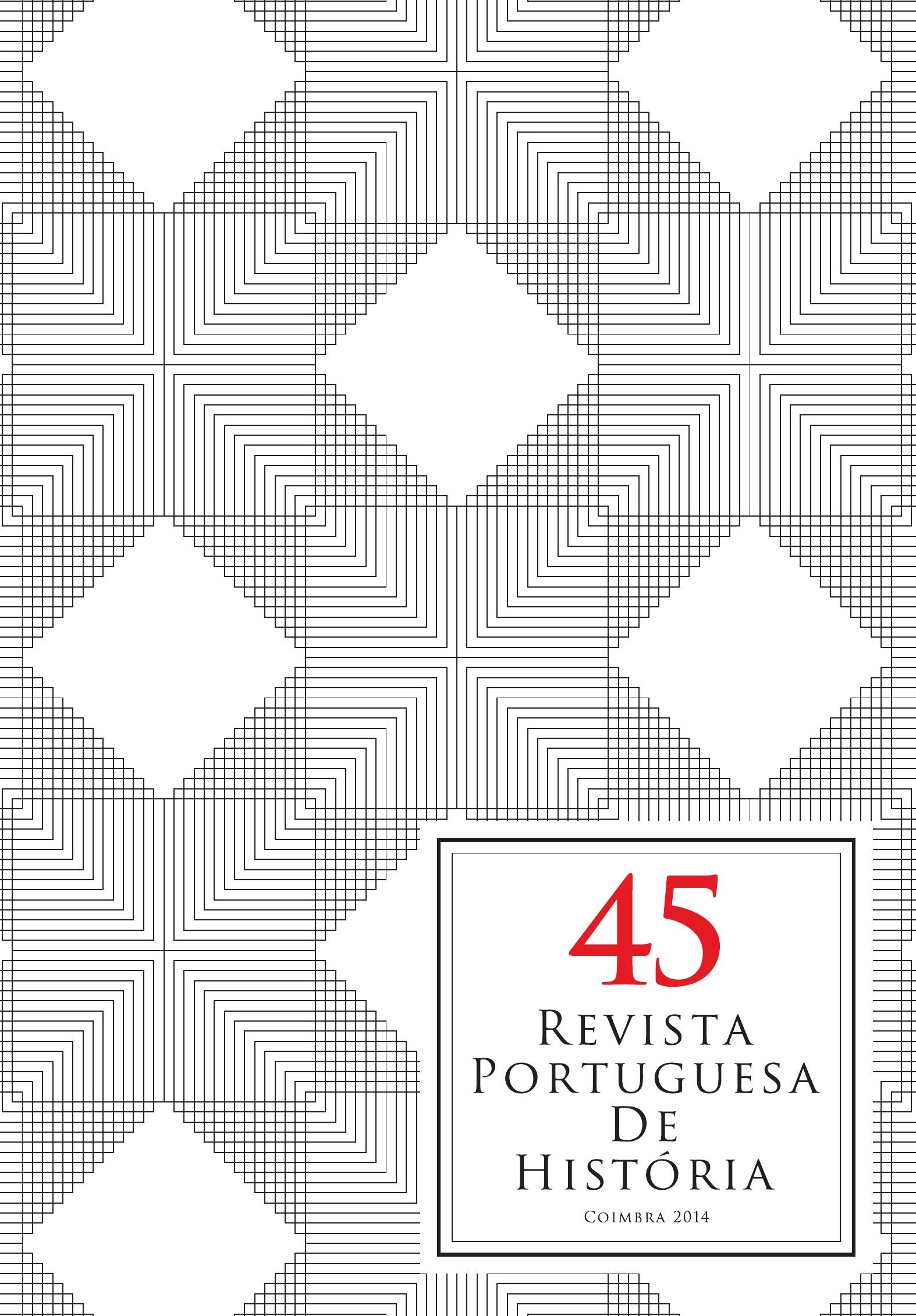




\title{
Cidade Universitária de Coimbra. Património e exaltação
}

\author{
The University town of Coimbra: Patrimony and Exaltation
}

\begin{abstract}
Nuno Rosmaninho
Investigador integrado do Centro de Línguas e Culturas da Universidade de Aveiro (CLC) e investigador colaborador do Centro de Estudos Interdisciplinares do Século XX da Universidade de Coimbra (CEIS20

rosmaninho@ua.pt
\end{abstract}

\section{Resumo:}

O presente artigo esboça uma história da recepção estética e política da cidade universitária de Coimbra edificada pelo Estado Novo. O objectivo é detectar as transformações que acompanharam a sua elevação a património mundial da UNESCO (2013) e, em particular, contextualizar o clamor dos estudantes contra as inscrições partidárias na escadaria monumental (Maio de 2011). Para isso, a recepção crítica é dividida em cinco períodos definidos pela tónica dos discursos: o fascínio pela «grandeza» das obras que se anunciam (1934-1941); a interpretação política da monumentalidade arquitectónica e urbanística (1941-1966); a tardia valorização do núcleo histórico urbano e o vigor crescente dos juízos estéticos e políticos negativos (1966-1990); o predomínio das interpretações historiográficas (1990-2011); o reinvestimento simbólico e afectivo (a partir de 2011).

\section{Palavras-chave:}

Universidade de Coimbra; património mundial da UNESCO; Estado Novo; Escadas Monumentais.

\section{Abstract:}

This essay aims at outlining the background to the political and aesthetic reception of the University town of Coimbra built by the Estado Novo (New State). The goal is, therefore, to uncover the transformations associated with its being ranked as World Heritage site by UNESCO (2013) while contextualizing the students' outcries against the political parties' slogans/graffiti inscribed on its adjacent monumental staircase (May of 2011). To this aim, the critical reception is divided into five periods so as to highlight the emphasis put on the discourse of each particular one: the fascination aroused by the announcement of the "greatness" in these buildings (1934-1941); the political interpretation of this architectural urban monumentality (1941-1966); the late appreciation of this urban historical site and the vigorous crescendo underlying the negative aesthetic and political remarks (1966-1990); the prevalence of historiographical interpretations (1990-2011); and the symbolical and affectionate reinvestment (after 2011).

Keywords:

University of Coimbra; UNESCO world heritage site; Estado Novo/New State; Monumental Staircase. 
O presente artigo começou por ser uma reflexão sobre os aspectos mais recentes da patrimonialização da cidade universitária de Coimbra construída durante o Estado Novo. Em Maio de 2011, muitos estudantes reagiram com desagrado à pintura de frases políticas nas escadas monumentais. O que durante décadas fora aceite com naturalidade transformou-se num acto de vandalismo. A reacção intempestiva dos alunos surpreendeu muita gente. Estariam eles cientes do que estavam a dizer? A pergunta traduzia dúvida e incompreensão. Acolhi o convite para palestrar no Ateneu de Coimbra, em 31 de Outubro de 2013, como uma oportunidade de tornar compreensível esses factos que, ocorridos durante uma campanha eleitoral, agitaram os meios de comunicação e provocaram actos de hostilidade em relação a um partido político. O que apresentei no Ateneu pode agora ser reexaminado. Não está em causa directamente a classificação como Património Mundial da UNESCO, mas os fenómenos colectivos que acompanham essa consagração.

Havia uma grandeza no título da palestra que se preserva nesta versão escrita. A epígrafe talvez levasse a pressupor um discurso de louvor e glorificação, aliás consonante com o que se observava quase diariamente desde que, quatro meses antes, a UNESCO distinguira aquele conjunto urbano. A intenção era colocar-me e aos que me ouviam no itinerário que conduziu à atitude dos estudantes. Não duvido que há sempre uma dimensão identitária no património. No entanto, quando as palavras se gastam, talvez seja preferível dizer de outra maneira. Património e exaltação são palavras redundantes. Foi isso que procurei mostrar e que algumas reacções do público evidenciaram.

Uso o termo exaltação nos seus literais e contraditórios sentidos, que o Dicionário da Língua Portuguesa Contemporânea, da Academia das Ciências de Lisboa, anota em três pontos principais: 1. «Elogio, louvor de alguém ou alguma coisa ao mais alto nível dos méritos, virtudes ou qualidades»; 2. «Agitação, ansiedade do espírito, caracterizada por ideias e os sentimentos, intensos, exacerbados, excessivos»; 3. «Estado de irritação, de cólera.»

A defesa, a classificação e a destruição do património fazem-se com exaltação. O clamor dos estudantes contra a «vandalização» das escadas monumentais é mais um episódio dessa atitude que nasceu com o Romantismo e permanece como um dos principais motores de protecção e de perda. É próprio do património ser tratado com exaltação no elogio, no desprezo e na cólera, sobretudo desde que o século XIX lhe acrescentou um poderoso sentido identitário.

Nas páginas que se seguem, observo a recepção do património da cidade universitária de Coimbra na suposição de que equivale a uma constante reinvenção afectiva. 


\section{A exaltação do futuro: uma promessa de grandeza (1934-1941)}

No início do Estado Novo, a universidade de Coimbra ocupava velhos edifícios anteriores ao século XIX. Mesmo a recente Faculdade de Letras adaptara um imóvel concebido para teatro. Numa época em que os núcleos históricos urbanos eram correntemente depreciados, os arruamentos tortuosos e a coexistência de prédios residenciais davam ao conjunto universitário uma feição híbrida e algo trivial, desagradável para a forte corrente «progressista» que, em nome dos valores da higiene e da monumentalidade, condenava as zonas históricas das cidades. Até à década de sessenta, os defensores da Alta agiam na defensiva, cientes de que não tinham instrumentos de patrimonialização que pudessem contrapor ao forte impulso de remodelação proveniente dos arquitectos, urbanistas, políticos e da própria opinião pública.

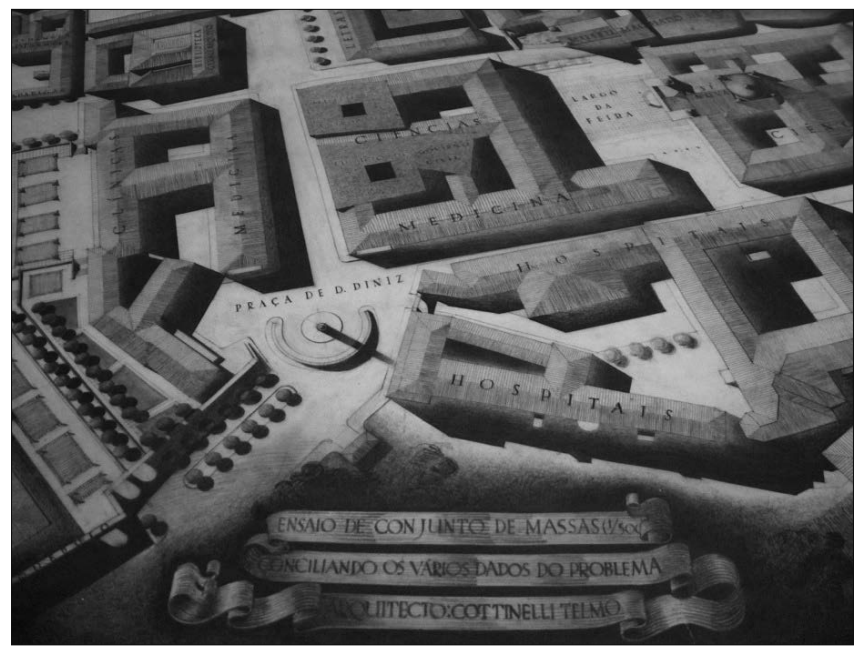

Cottinelli Telmo, Ensaio de conjunto de massas conciliando os vários dados do problema, 1942. (Fonte: NATCE - Núcleo de Arquivo Técnico de Construções Escolares, Divisão de Documentação e do Património Cultural da Secretaria Geral do Ministério da Educação)

Em 1934, quando o governo tornou pública a decisão de criar em Lisboa uma cidade universitária, Coimbra reclamou a «valorização» das instalações da Alta. Por um lado, não era financeiramente plausível solicitar uma cidade universitária inteiramente nova. Por outro, esse intuito seria absurdo atendendo ao valor simbólico da localização no topo da acrópole. O que se discutiu desde o 
primeiro instante foi apenas uma «remodelação». As ideias do engenheiro Abel Urbano num jornal local e os planos das duas primeiras comissões de obras têm em comum o intuito de melhorar as instalações através da ocupação dos quarteirões residenciais. Essa é também a ideia apresentada por Oliveira Salazar no prefácio ao volume II dos Discursos, datado de 1 de Dezembro de 1937. Os bairros antigos eram zonas de intervenção livre, como se deduz da persistente intenção de reconstruir a Baixa a partir de arrasamentos sistemáticos.

Nestas circunstâncias, a remodelação exprimia a contenção de quem pensava não poder aspirar a maior ruptura e grandiosidade. O projecto foi recebido com íntimas dúvidas, sobretudo em Coimbra. A promessa de grandeza situava-se num futuro longínquo, como se fosse uma improvável «reforma pombalina». Há belas palavras de expectativa. No entanto, talvez não seja exagerado dizer que, nesta fase, só Duarte Pacheco acreditou na possibilidade de ultrapassar os retoques urbanos e fazer algo completamente novo e excepcional. Enquanto ministro das Obras Públicas, recusou as propostas da primeira comissão de obras (1936), modificou de modo significativo o programa da segunda (1940) e, quando quis passar à acção, chamou o arquitecto Cottinelli Telmo e desenhou com ele uma visão majestosa.

No dia 1 de Fevereiro de 1940, o reitor comunicou ao senado da universidade que o governo pretendia começar os trabalhos. E em 15 de Outubro do ano seguinte, saiu em Diário do Governo o decreto-lei criando a comissão encarregada de os realizar. Ainda que as dúvidas pudessem persistir, este facto encerrou a fase das promessas. Quando os proprietários começaram a ser notificados das expropriações, em Fevereiro de 1942, o futuro e a utopia ganharam uma dimensão real e questionável.

\section{A exaltação do regime: uma promessa de monumentalidade (1941- -1966)}

Para compreender os primeiros quinze anos de obras, é necessário lembrar que permanece vivo o desprezo pelos núcleos históricos urbanos. A ideologia «progressista» eleva as demolições a princípio renovador das cidades e a população aceita-as como inevitáveis e benignas. A defesa da Alta restringe-se aos tradicionalistas. As apresentações do novo plano da «cidade universitária» (é sempre esta a expressão utilizada) salientam a grandeza e a monumentalidade. O Diário de Coimbra de 1 de Janeiro de 1950 enuncia aquilo que agora fascina e que o tempo tornará lugares-comuns: a «grande artéria» da Rua Larga, a «monumental» Praça de D. Dinis, a «Grande Praça da Porta Férrea». Esta promessa de monumentalidade vale muito mais do que as duas centenas de pré- 
dios que é necessário destruir. No jornal académico $O$ Ponney, um articulista que se subscreve com as iniciais A.S.B. não hesita. As «velhas construções sem interesse» desaparecem «para no local se erguerem espaçosos patamares de longas escadarias decoradas com estátuas e obras de arte».

O entusiasmo é urbanístico, estético e político. A ideia de regeneração urbana continha traços messiânicos. Carminé Nobre, chefe de redacção do Diário de Coimbra, não precisou de conhecer o plano exacto para o perfilhar. Em 16 de Dezembro de 1941, escreveu: «A Cidade Universitária é uma velha aspiração que em breve começará a ser uma realidade presente, que aos nossos olhos aparece cheia de esperança, como indício de uma rajada de vento que passe por esta terra e lhe dê uma fisionomia moderna e cheia de cor.» Em 22 de Abril do ano seguinte, a cidade universitária ainda se lhe apresenta como a «obra gigantesca que Coimbra, de facto, há muito merece». Em 3 e 4 de Fevereiro de 1945, o Diário de Coimbra, encontrando-se sob a direcção interina de Manuel Deniz Jacinto, membro do Partido Comunista, inseriu dois artigos programáticos valorizando a grandiosidade das obras, propondo mais demolições e silenciando os protestos motivados pelas expropriações e pelos realojamentos. Três meses decorridos, António Macedo, presidente da Associação Académica em 1929-30 e 1930-31, opositor do Estado Novo e futuro fundador do Partido Socialista, defendeu, em palestra na antiga Faculdade de Letras, a conveniência das demolições em nome de «uma cidade universitária moderna».

O próprio entusiasmo político vive da volúpia demolidora, que representa energia e determinação. O cineasta e jornalista António Lopes Ribeiro interpreta esse «progressismo» sem freio. Em 29 de Agosto de 1948, exaltou a onda de demolições como o reverso das qualidades empreendedoras do regime. Entusiasmado pelas «cidades civilizadas, limpas, habitáveis e transitáveis», despreza o saudosismo urbano e o apego pelas coisas antigas, justifica destruições pela fealdade, quer a história nos museus e não nas ruas. «Em Lisboa, onde escrevo, e em Coimbra, onde se publicam estas linhas, vai todo um frenesi demolidor», afirma ele. «As duas tarefas - demolir e construir - são complementares e inseparáveis.» Efectivamente, parecia não haver limites. No ano seguinte, apesar de o aqueduto de São Sebastião se encontrar classificado, o ministro das Obras Públicas, numa visita ao local, decretou a demolição de seis arcos para «desafrontar» o Colégio de S. Bento e suavizar o declive da Ladeira do Castelo. Os jornais fizeram o anúncio com placidez, sem o mais leve comentário.

As escadas monumentais exprimem bem esse período de fastígio monumental, em que a opinião pública e o regime concordavam na alteração violenta da Alta. Foi Duarte Pacheco que se iludiu com o eixo da nova Rua Larga 
e dos Largos da Porta Férrea e de D. Dinis estendendo-se pela encosta. Esse desejo, tão nítido nas peças desenhadas, é irremediavelmente prejudicado pelo grande desnível. Mas marca uma intenção. É um símbolo do projecto urbano e da acção política.

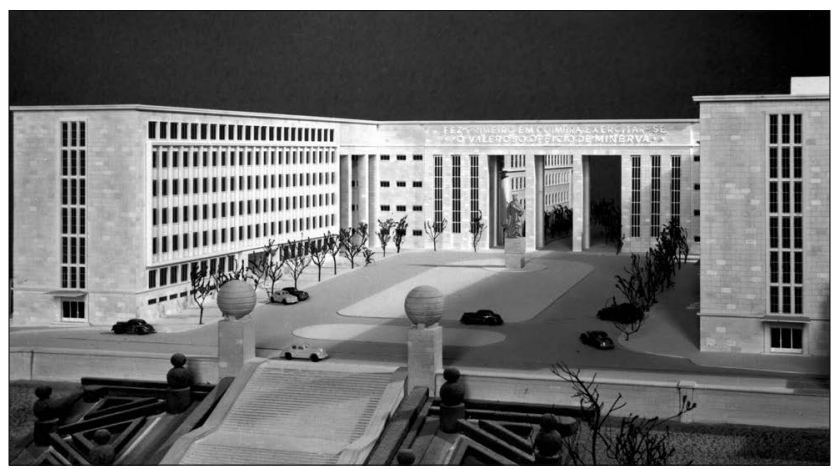

Pormenor da maqueta da cidade universitária de Coimbra. (Fonte: NATCE)

As críticas à cidade universitária são circunstanciais e, fora dos directamente prejudicados, pouco veementes. É verdade que os proprietários dos prédios residenciais e os arrendatários dos estabelecimentos comerciais se opõem aos iníquos procedimentos expropriativos, apresentam duras reclamações colectivas a Oliveira Salazar, preparam-se para o pior e acabam espoliados por valores inferiores aos da matriz predial. É um facto que o historiador de arte António Nogueira Gonçalves se preocupa com as demolições realizadas sem acompanhamento arqueológico e sem o aproveitamento das partes mais valiosas. No entanto, um a um, os colégios foram marcados para a destruição e poucas pessoas se opuseram ou protestaram.

As objecções políticas são quase impossíveis em face do apoio generalizado ao plano de conjunto. Aos ouvidos da comissão de obras, chegou a informação de que o professor da Faculdade de Ciências Mário Augusto da Silva afirmava que o que o regime pretendia era «apenas obra de fachada monumental para deslumbrar o pacato burguês ou o visitante em digressão turística». Viria a ser aposentado compulsivamente, por motivos políticos, em Abril de 1948. Esta opinião destoava no coro de elogios.

As demolições chegam a parecer inevitáveis e insusceptíveis de contestação. Criticam-se quando muito os atrasos. Os tradicionalistas não podiam deixar de lamentar o que ia desaparecendo. Um exemplo é António Cabral, o tra- 
dicionalista triste. Mas a sua reacção é de pesar e não de fúria ou de combate. $\mathrm{E}$ isto mostra como se encontra na defensiva e sem armas para contestar o discurso «progressista» dominante. Este velho jurista e político, deputado em 1895 e ministro das Obras Públicas (1905) e da Marinha e do Ultramar (1909), contando já mais de oitenta anos, expôs em 1947, no prefácio à segunda edição de Tempos de Coimbra. Memórias de Estudante, um desalento absoluto: «Trocaram-me a linda Coimbra, a Coimbra romântica da minha alegre juventude. Que dor! Por todas aquelas ruas estreitas, agora talvez embaraçadas pelo entulho, passei e corri centenas de vezes; em algumas daquelas casas, hoje demolidas, conversei com exuberância e ri com alegria. Havia então ruído e ar, onde, a esta hora, certamente só haverá silêncio e pó.»

A opinião que parecia ilustrada e impante era a que minimizava as destruições em nome do progresso e da higiene urbana. Jorge de Seabra representa melhor que ninguém este tempo de certezas. Já estamos em 1963 e este antigo estudante, licenciado em Direito em 1918, continua a referir-se com displicência ao «arejo», à «salutar espanadela», que baniu «certas excrescências», «prédios inestéticos», «cafés manhosos», quarteirões que «nada ou muito pouco valiam como raridades urbanísticas». O seu enlevo vai para os novos arruamentos largos e sumptuosos e para os imóveis «amplos», «modernos», «airosos», «imponentes», «nobres» e «dignos».

No período seguinte, este entusiasmo político e estético não desaparece, mas perde preponderância, torna-se defensivo e pouco convincente.

\section{A exaltação anti-salazarista: uma promessa de desprezo (1966-1990)}

Em 1966, o arquitecto Cristino da Silva, que sucedera a Cottinelli Telmo na direcção das obras e mantivera a orientação monumental, abandonou o cargo por limite de idade. A Sociedade de Defesa e Propaganda de Coimbra organizou uma exposição da Alta destruída que favoreceu uma rememoração saudosa, avivou a consciência de perda patrimonial e desencadeou significativas manifestações de descontentamento. O Século Ilustrado colheu depoimentos que coincidiam no desprezo pelo novo empreendimento e na valorização do bairro desaparecido. Nesta nova fase, até o senado universitário criticou o plano, a localização e as demolições. No segundo volume da autobiografia, Ruben A. menosprezou os edifícios construídos ao «estilo germânico-nazista». Em 1967, o arquitecto Francisco Keil do Amaral apontou à escadaria monumental a desmesura, a ausência dos «princípios clássicos», a falta de corrimão e as próprias esferas terminais «que os citadinos designam melancolicamente por “este mundo e o outro"». No ano seguinte, o arquitecto José Pedro Martins 
Barata, convidado a dar um parecer sobre a Praça de D. Dinis, refutou os preceitos basilares da cidade universitária, lamentou a sua imposição forçada num «ambiente histórico medieval e renascentista» e recomendou o abandono dos icónicos pórticos.

No declinar do Estado Novo, acentua-se o desprezo estético. A recepção crítica faz-se com um léxico sombrio. Os imóveis são caixotes, casarões monótonos, pesados, acachapados, cinzentos, tristes, taciturnos, carrancudos, façanhudos. Mas o que melhor define esta terceira etapa é a condenação global da cidade universitária. Assim como nos anos quarenta e cinquenta havia um padrão de elogio, desenvolve-se a partir de agora uma norma depreciativa. O seu vigor provém da interpretação política da cidade universitária. A condenação estética não se compreende sem a condenação ideológica. A destruição do «núcleo histórico urbano» vale como uma marca de prepotência. Escreve-se sobre a cidade universitária para denunciar erros, fealdades e violências.

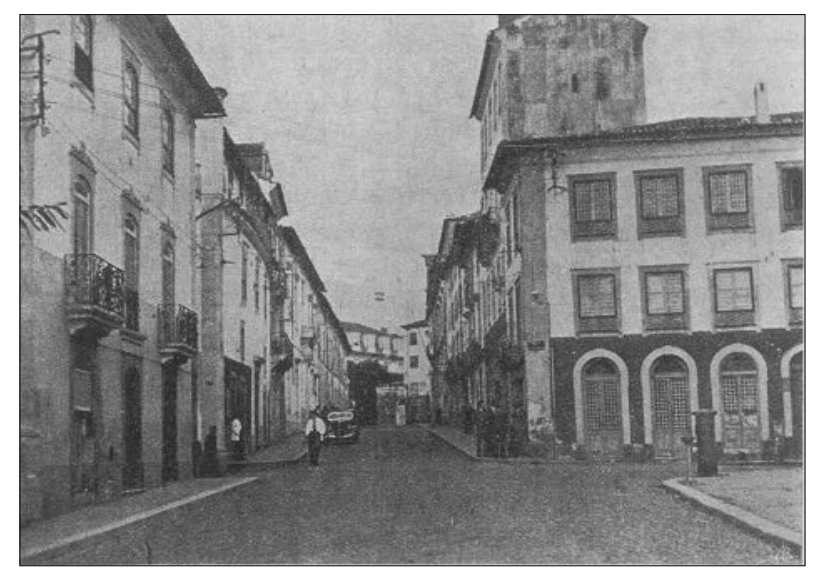

Rua Larga antes das obras da cidade universitária de Coimbra.

(Fonte: Diamantino Calisto, Costumes Académicos de Antanho, Porto, Imprensa Moderna, 1950)

Em 1974, Cristóvão de Aguiar, leitor da Faculdade de Letras, aludiu no seu diário à «criminosa» demolição da Alta. Dez anos depois, no Boletim da Associação dos Antigos Estudantes de Coimbra, Antonino Henriques escreveu sobre o «camartelo de má memória», o «atentado contra o valioso e multifacetado património histórico-tradicional», a destruição inglória, insensível, irresponsável e selvática. Em 1985, na série de artigos publicados na Tribuna de Coimbra, Carlos Santarém Andrade, que foi director da Casa da Cultura, 
falou em «erro tremendo», desprezou a «grandiosidade monolítica» e a monotonia, e evocou com mágoa o «belo barroco das casas antigas» e a perda dos espaços de antigas vivências estudantis.

Estas atitudes são naturais e legítimas. Em nenhum momento pretendo diminuí-las ou desacreditá-las. Na verdade, elas prolongam-se até à actualidade. Em 1991, o arquitecto Carlos de Almeida destaca a prepotência do regime e o «servilismo dos seus acólitos e mercenários aduladores». Em 1992, o director da revista Munda, Mário Nunes, continua a reprovar a «megalomania geral do conjunto». E ainda hoje este discurso ocorre com uma naturalidade quase automática. No entanto, os anos noventa, colhendo destas formulações as raras tentativas de estudo, ensaiaram um esforço sistemático de aclaração do que foi o processo de construção da cidade universitária.

\section{A exaltação compreensiva: uma promessa de aceitação (1990-2011)}

Escolhi 1990 como data de viragem porque o estudo da obra de Coimbra se enquadra num processo de desenvolvimento da investigação sobre a universidade (neste ano comemorou-se com um grande congresso o sétimo centenário da sua criação em Portugal) e o próprio Estado Novo. Os ensaios «compreensivos» não começaram em 1990. Basta lembrar as menções de José-Augusto França em 1961, de Nuno Portas em 1973, de Artur Portela em 1982 e do arquitecto Sérgio Fernandez em 1985. Apesar das condenações estéticas, observa-se uma exegese diferente, que passa, entre outros aspectos, pela pesquisa de afinidades com o nazismo e o fascismo.

Se é verdade que nos anos oitenta se começou a estudar mais extensamente a cidade universitária (mantendo embora as apreciações negativas) e se alguns autores de referência há muito tinham apontado para as virtudes do comparatismo, a novidade da década de noventa reside na constância da pesquisa e na diversificação dos temas. Os estudiosos do Estado Novo querem compreender o regime e a sua arte. Neste esforço, abandonam o tom julgador da época anterior. Esse facto pode ser confundido com uma promessa de aceitação, embora vise apenas a neutralidade historiográfica. Não estava em causa a valorização patrimonial da cidade universitária salazarista, mas apenas uma vontade de isenção.

Neste período, procura-se conhecer melhor a Alta demolida, quantificando o número de prédios derrubados, deduzindo o valor locativo e cartografando a actividade comercial. Observa-se o exercício do poder e distingue-se a intervenção das diferentes entidades públicas. Pondera-se a destruição patrimonial (da arquitectura tradicional e erudita) e a reacção dos conimbricenses 
e da universidade. Analisa-se a aplicação do conceito de cidade universitária e procuram-se meios objectivos de medir a recepção crítica. Para tornar compreensíveis aparentes contradições ideológicas e sanar os facilitismos das interpretações políticas, desenhou-se um quadro histórico do imaginário de Coimbra. A arquitectura, a pintura e a escultura receberam sucessivos trabalhos de investigação incidindo na iconografia e nas dimensões «naturalista», «moderna», «clássica», «tradicional»e «monumental».

Os juízos negativos não desapareceram (nem tinham de desaparecer) mas perderam a dominância anterior, enquanto proliferavam os contributos historiográficos. Em 1990, o advogado Alberto Sousa Lamy publicou uma obra monumental sobre a história da Academia, onde estabelece a cronologia da destruição da Alta e enumera as críticas principais. No mesmo ano, Pedro Dias e António Nogueira Gonçalves incluíram os edifícios do Estado Novo no roteiro artístico da universidade e envolveram essa primeira panorâmica numa discreta caracterização estética.

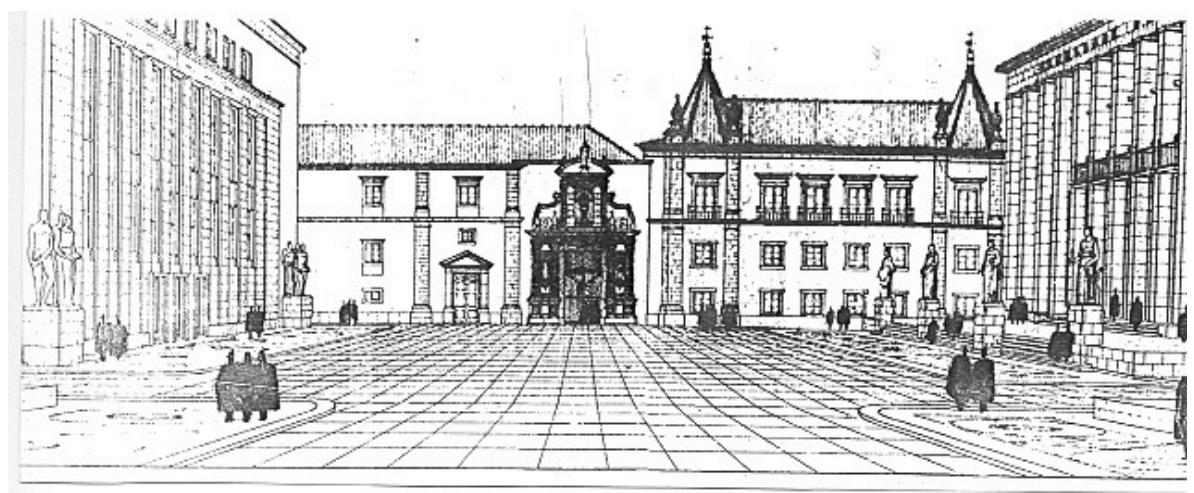

Antevisão da Praça da Porta Férrea depois de construídas a Faculdade de Letras e a Biblioteca Geral.

(Fonte: Centro de Arte Moderna da Fundação Calouste Gulbenkian, acervo Cristino da Silva)

Em 1991, Margarida Acciaiuoli associou a cidade universitária de Coimbra à visão das artes em Portugal nos anos quarenta. As críticas de Mário Bento não o impediram de salientar o contexto político e de ponderar a arquitectura e o urbanismo. Em trabalho policopiado apresentado na licenciatura em História, Maria Luísa Ferreira procedeu ao primeiro exame do acervo da Comis- 
são Administrativa do Plano de Obras da Cidade Universitária de Coimbra (CAPOCUC), que as diligências de Luís Reis Torgal permitiram localizar e integrar no Arquivo da Universidade.

Em 1993, no âmbito da licenciatura em Arquitectura, Rui Pedro Lobo e outros quatro alunos procederam ao primeiro estudo do edifício da Associação Académica, projectado por Alberto José Pessoa e João Abel Manta. Três anos depois, editei os planos das comissões dos anos trinta, e no prefácio Luís Reis Torgal discutiu o conceito de cidade universitária, contrariou o mito de ela ter sido uma obra «do próprio Salazar» e duvidou muito legitimamente da ideia-feita de que a maioria da população se teria oposto. Em 1998, a revista Monumentos dedicou um número à universidade de Coimbra onde, entre outros autores, Sandra Vaz Costa estudou a «escultura monumental». Na sua prova final de licenciatura, a arquitecta Ana Patrícia Claro Ribeiro dedicou algumas páginas à revolução urbanística operada pelo Estado Novo.

Em 1999, enquanto se iniciava o anfiteatro da Faculdade de Direito projectado por Fernando Távora, Luís Reis Torgal publicou A Universidade e o Estado Novo, onde, entre outros assuntos, tipifica a «arquitectura de Poder» dos regimes autoritários e totalitários, analisa a reacção da universidade e o problema das demolições e dos realojamentos, e desmistifica a ideia de uma contestação «liderada pela "esquerda" estudantil». Na prova final da licenciatura em Arquitectura, Sílvia Benedito escreveu sobre Expressão Fascista? O percurso da Cidde Universitária de Coimbra como expressão de uma arte política. Em 2001, apresentei a dissertação de doutoramento intitulada $O$ Poder da Arte. O Estado Novo e a cidade universitária de Coimbra. Marco Daniel Duarte publicou, em 2003, Faculdade de Letras da Universidade de Coimbra: Ícone do Poder. Ensaio iconológico da imagética do Estado Novo.

Enfim, não é necessário prosseguir esta enumeração para comprovar a multiplicação e a diversidade de estudos. A «vontade de isenção» que eles manifestam traduz um esforço de contenção dos juízos negativos. Em vez de continuarem a denegrir política e esteticamente a obra do Estado Novo, os seus autores procuram minimizar o envolvimento subjectivo. No entanto, parece evidente que a objectividade tem por fim contrariar o impulso de repúdio estético e político, e portanto desenvolve-se sem pôr em causa o que se tem por intrinsecamente feio (salvo casos pontuais) e autoritário. A ideia de alguém defender a beleza geral da cidade universitária ou as suas virtudes simbólicas parecia longínqua e até absurda. E assim, quando os alunos protestaram contra a vandalização das escadas monumentais e alegaram o seu valor simbólico e identitário, a surpresa foi geral. 


\section{A exaltação do património: uma promessa de orgulho (2011 e ss.)}

Houve um tempo, como explicámos antes, em que o apreço pela cidade universitária era estético e político. Depois, esse forte amplexo volveu-se em desagrado manifesto ou recalcado. Agora, atenua-se a implicação política e regressa o gosto que já não é propriamente estético mas simbólico. No debate sobre a «vandalização» das escadas monumentais, não encontrei expressões de deleite artístico mas a reivindicação do seu carácter emblemático.

$\mathrm{Na}$ campanha para as eleições legislativas de 2011, a coligação CDU ocupou a totalidade da escadaria com a seguinte inscrição: «Nem propinas/Nem Bolonha/Mais bolsas!/Leva a luta até ao voto!» No lanço inferior, constavam as siglas e os símbolos do PCP e do partido Os Verdes. Estes apelos antecipavam o comício do PCP previsto para 24 de Maio. Nada de novo. O uso das Monumentais como cenário de propaganda partidária foi o do costume. Desde o 25 de Abril de 1974 que isso era uma rotina. A reacção de uma parte dos estudantes é que foi inesperada e logo diminuída por uma fracção substancial da opinião pública. $\mathrm{O}$ efeito contraproducente do menosprezo também surpreendeu muitas pessoas.

No blogue Aventar, um leitor resumiu a radicalização das atitudes nos seguintes termos: «Na manhã de dia 24 , a própria CDU chamou "ignorantes" a quem demonstrou o seu descontentamento na página CDU Coimbra (Facebook), e foi aí que as coisas realmente descambaram por parte de quem comentava». A exasperação conduziu ao boicote do comício da CDU e a uma primeira e durável interpretação dos factos, lida no mesmo blogue: «tudo o que se disse contra a pintura que no domingo a CDU fez nas escadas monumentais em Coimbra não passou de uma tentativa de direita de silenciar um partido de esquerda».

$\mathrm{Na}$ verdade, muitos comentários contêm um vincado anticomunismo. $\mathrm{Na}$ perspectiva insultuosa, de um lado estaria a «comunistada da trampa», do outro «imbeciloides» a «treinar o regresso ao passado», os primeiros desvalorizando a praxe e mantendo vivo o anti-salazarismo, os segundos invocando a tradição académica e o carácter patrimonial da escadaria. Uns, reclamando a liberdade de as pintar, os outros exigindo a liberdade de não as ver pintadas. Uns crendo que as Monumentais ainda poderiam ser destruídas sem perda, os outros invocando a proibição de realizar inscrições no Mosteiro dos Jerónimos e no Convento de Mafra.

Seria portanto absurdo dizer que as circunstâncias políticas estiveram totalmente ausentes nesta ocasião. É natural, aliás, que o processo de afastamento da obra em relação ao contexto salazarista levante objecções calorosas. 
No entanto, isto não constituiu propriamente uma novidade interpretativa. O debate patrimonial e simbólico afigurou-se mais relevante.

Os defensores das incrições fizeram uso dos velhos juízos. O blogger de Aventar considerou as escadas uma «aberração arquitectónica e urbanística» e espantou-se que chegassem «a chamar monumento nacional ao mamarracho». Uma volta pela blogosfera demonstra, porém, que elas tinham sido sujeitas nos últimos anos à apropriação simbólica e à mitificação. $\mathrm{O}$ que antes era ironia espalhou-se com o valor de «lenda».

A «famosa escada monumental», com os seus cincos lanços, representaria os cinco anos dos «antigos» cursos. Se o estudante tropeçar (ou cair?), reprovará no ano correspondente ao lanço onde o facto se der. Noutros sítios, escreve-se que «o número de vezes que se tropeçava nas escadas equivalia ao número de cadeiras a que se reprovava em cada ano». Os globos correspondem aos testículos da estátua de D. Dinis, que fica próxima, e cairiam «no dia em que sair uma rapariga virgem da universidade». Estas e outras velhas apreciações, antes expostas com sarcasmo, tocam o referido estatuto «lendário». As escadas são «um dos palcos da praxe coimbrã». Elas «simbolizam as dificuldades no caminho para o conhecimento... daí serem extensas e difíceis de subir».

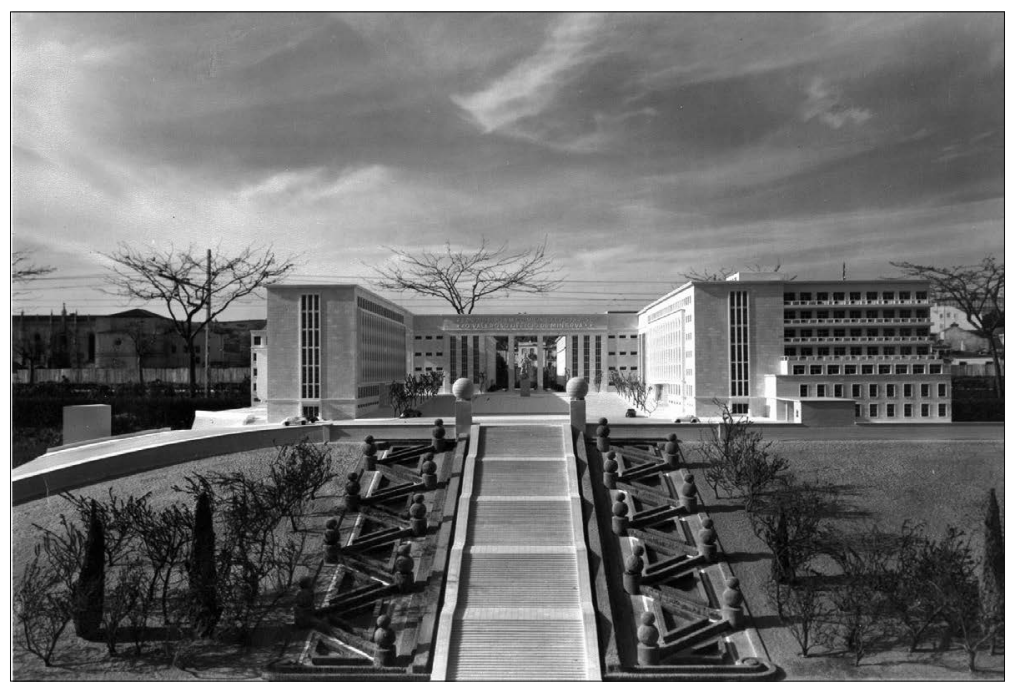

Maqueta da cidade universitária de Coimbra: escadaria monumental e Praça de D. Dinis. (Fonte: NATCE) 
Foi a nova dignidade simbólica concedida às Monumentais (e não a sua beleza) que levou os detractores das inscrições a protestar contra o «vandalismo». Os defensores alegaram que «pintar as monumentais é uma tradição desde 1974». Eis a resposta: «Pintar os monumentos é uma tradição? Não, pintar os monumentos, antes e depois do 25 de Abril, é condenável, às vezes autênticos crimes contra a cultura, é o que é.» Mas as monumentais são um «monumento»? A ideia de que estava em curso o processo de classificação pela UNESCO animava os que diziam que sim e irritava os que pensavam que não. Uns exageravam dando por adquirido o estatuto de património mundial. Outros diziam que, pelo contrário, «a qualificação da zona candidata implica[va] mexer nas monumentais», eufemismo que incluía uma esperança de destruição. No calor da disputa, o blogger de Aventar defendeu que o destino daquele «mamarracho» teria «de passar pela demolição».

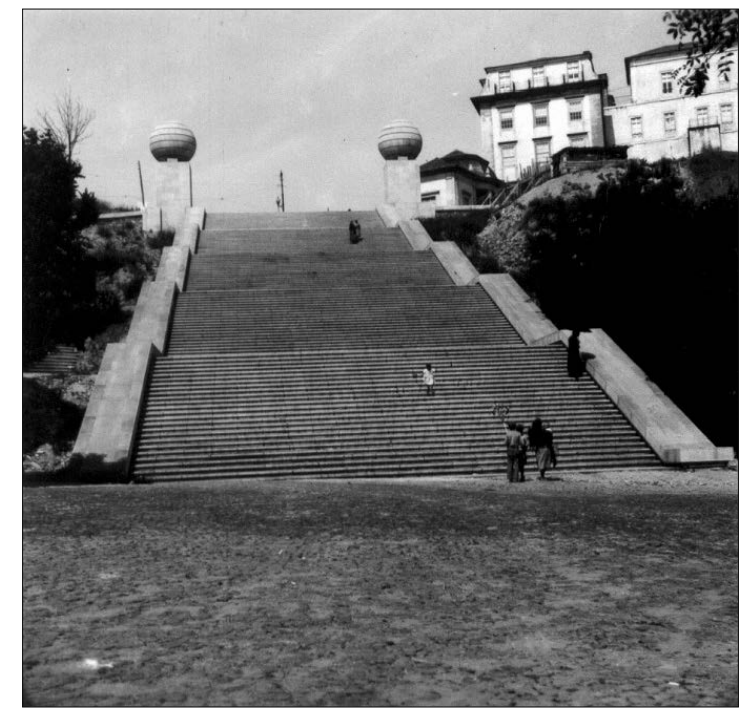

Cottinelli Telmo, Escadaria monumental da cidade universitária de Coimbra, 1944-1949. (Fonte: NATCE)

Com posições extremadas, uma das notas mais inovadoras é a de uma estudante que, intrerpretando o novo sentido de pertença, afirma que «as Escadas sempre foram importantes para nós de algum modo». E a de um aluno explicando que elas, «goste-se ou não, fazem parte de Coimbra e de alguma da sua história». Aqui chegados, torna-se legítimo postular a proibição das inscrições com a seguinte pergunta: «Porque não pintaram a Torre de Belém? Qual seria 
a diferença?» E portanto: «Bonitas ou feias, sejam de que regime for, as escadarias e as paredes não são para serem borradas, é o termo.» Está consumada a reinterpretação identitária das Monumentais. No dia 27 de Maio de 2011, o Opinador de Veludo deu-lhe uma síntese definitiva: «A escadaria monumental faz parte desse núcleo de edifícios, visitados diariamente por inúmeros turistas e que, mais do que isso, pertencem a todos nós, sendo já um domínio definidor do nosso sentimento de Nação.»

As Monumentais haviam sido inseridas, um mês antes, na Zona Especial de Protecção decorrente da candidatura da Alta universitária a património mundial da UNESCO. Este facto tornou ilícitas as pinturas realizadas livremente durante quase quarenta anos e conduziu três dirigentes do PCP ao banco dos réus. Três anos depois, os militantes foram absolvidos embora se tenha provado a prática do crime de que iam acusados. O tribunal reconheceu que o novo enquadramento não era conhecido pela generalidade da população.

A discussão mal se reacendeu. O tom polémico de 2011 estava ultrapassado. O valor patrimonial, e portanto identitário, tornara-se um dado adquirido e remetia para segundo plano os dilemas políticos controvertidos desde os anos trinta. O título de património mundial alcançado em 23 de Junho de 2013 veio apaziguar os ânimos e dar primazia à orientação patrimonialista que alimentara os protestos contra as inscrições. Não justificou o anticomunismo, mas integrou as Monumentais numa dignidade que a muitos ainda custa aceitar.

\section{Bibliografia}

A., Ruben - O mundo à minha procura: Autobiografia, Volume II, Lisboa, Parceria A. M. Pereira Lda., 1966.

Acciaiuoli Homem de Campos Tavares de Brito, Margarida - Os Anos 40 em Portugal: o país, o regime e as artes: "restauração" e "celebração". Dissertação de doutoramento em História da Arte Contemporânea apresentada na Faculdade de Ciências Sociais e Humanas da Universidade Nova de Lisboa, em Junho de 1991. Policopiada.

Aguiar, Cristóvão de - Relação de bordo (1964-1988): diário ou nem tanto ou talvez muito mais, Lisboa, Campo das Letras, 1999.

Almeida, Carlos de - Crónicon conimbrigense, Coimbra, Edição do Teatro Avenida, s. d. (1991?).

Amaral, Francisco P. Keil do; Bárbara, José de Santa - "Arte urbana”, Arquitectura. Revista de arte e construção, Lisboa, 97 (Maio e Junho de 1967) p. 120-126.

Andrade, Carlos Santarém - "Vida e morte da Alta de Coimbra. 4 - Nas vésperas da destruição", A Tribuna de Coimbra, Coimbra, ano 0, n. ${ }^{\circ} 25$, quartafeira, 30 de 
Outubro de 1985, p. 5; "Vida e morte da Alta de Coimbra. 5 - "Delenda Coimbra", idem, n. ${ }^{\circ}$ 26, quartafeira, 6 de Novembro de 1985, p. 5; "Vida e morte da Alta de Coimbra. 6 - Foi um erro tremendo", idem, n. ${ }^{\circ} 27$, quartafeira, 13 de Novembro de 1985 , p. 5.

B., A. S. - "O que dizem... de Coimbra!!”, O Ponney, Coimbra, ano XXIV, n. 372 , 27 de Maio de 1952, p. 55 (inumerada).

Bandeirinha, José António Oliveira - "Os edifícios da Associação Académica e o Teatro de Gil Vicente”, Monumentos, Lisboa, 8 (Março de 1998) p. 83-87.

Benedito, Sílvia - Expressão Fascista? O percurso da Cidde Universitária de Coimbra como expressão de uma arte política, Coimbra, 1999. Prova final da licenciatura em Arquitectura, policopiada.

Bento, Mário Augusto S. - Conservação, restauro, reabilitação. ideologias e práticas, Coimbra, 1994.

Cabral, António - Tempos de Coimbra: memórias de estudante, Coimbra, Coimbra Editora, 1925. (2. ' edição, intitulada Tempos de Coimbra: memórias de estudante: anedotas e casos, figuras e tipos, 1947; 3. a edição, 1962.)

“Cidade Universitária. Antevisão da Praça da Porta Férrea”, Diário de Coimbra, ano XX, n. ${ }^{\circ}$ 6354, domingo, 1 de Janeiro de 1950, pp. 1 e 9.

Corregedor, João - "Coimbra é uma lição, mas o tempo não volta para trás...", O Século Ilustrado, Lisboa, ano XXIX, n. . 1476, 16 de Abril de 1966, pp. 23-27, 35-36 e 41. Fotografias de E. Gageiro.

Costa, Sandra Vaz - “A escultura monumental”, Monumentos, Lisboa, 8 (Março de 1998) p. 7980.

Dias, Pedro; Gonçalves, António Nogueira - O património artístico da universidade de Coimbra, Coimbra, Universidade de Coimbra, 1990.

DuARTE, Marco Daniel - Faculdade de Letras da Universidade de Coimbra: ícone do poder: ensaio iconológico da imagética do Estado Novo, Coimbra, Câmara Municipal de Coimbra, 2003.

FERnANDEZ, Sérgio - Percurso: arquitectura portuguesa (1930-1974), 2. edição, Porto, Faculdade de Arquitectura da Universidade do Porto, 1988. (1. a edição, do autor: 1985.)

Ferreira, Maria Luísa Fernandes - O Estado Novo e a construção da cidade universitária de Coimbra, Coimbra, Faculdade de Letras, 1991. Trabalho policopiado. Fonseca, Fernando; Freddy; Antunes, Paulo; Silva, Rui Afonso; Lobo, Rui Pedro Os cinco na AAC: livro de aventuras, Coimbra, Faculdade de Ciências e Tecnologia da Universidade de Coimbra, 1993. Trabalho policopiado.

FrançA, JoséAugusto - A arte em Portugal no século XX (1911-1961), 2. a edição revista, Venda Nova, Livraria Bertrand, 1985. 
Henriques, Antonino - “Aqui morou... Lápides evocativas de antigos estudantes de Coimbra", Boletim da Associação dos Antigos Estudantes de Coimbra, Coimbra, 14 (Junho de 1984) p. 29-46.

JACINTO, Deniz?] - "A Cidade Universitária de Coimbra”, Diário de Coimbra, Coimbra, ano XV, n. ${ }^{\text {os }} 4959$ e 4960, sábado e domingo, 3 e 4 de Fevereiro de 1945 , pp. 1 e 14.

LAmy, Alberto Sousa - A academia de Coimbra (1537-1990), Lisboa, Rei dos Livros, 1990.

Macedo, António - Da academia do meu tempo aos estudantes de amanhã, Porto, s. e., 1945.

Nobre, C[arminé] - “A Cidade Universitária”, Diário de Coimbra, ano XII, n. 3863 , terçafeira, 16 de Dezembro de 1941, p. 1.

Nobre, Carminé] - "Camões esquecido e maltratado já não tem monumento nem lápide em Coimbra”, Diário de Coimbra, ano XVIII, n. ${ }^{\circ}$ 5436, terçafeira, 10 de Junho de 1947, p. 1.

Nobre, Carminé?] (entrevistador); Correia, Maximino (entrevistado) - "Expropriar e demolir", Diário de Coimbra, ano XII, n. . 3986, quartafeira, 22 de Abril de 1942, p. 1 .

Nunes, Mário - "Os frescos da Faculdade de Letras da Universidade de Coimbra", Munda, Coimbra, 23 (Maio de 1992), p. 29-34.

Portas, Nuno - "A evolução da arquitectura moderna em Portugal: uma interpretação" in Bruno Zevi, História da Arquitectura Moderna, volume II, Lisboa, Editora Arcádia, 1973, p. 687-744.

PORTELA, Artur - Salazarismo e artes plásticas, 2. ${ }^{\text {a }}$ edição, Lisboa, Instituto de Cultura e Língua Portuguesa, Ministério da Educação e Cultura, 1987. (1. a edição, 1982).

RIBEIRo, Ana Patrícia Claro - Coimbra: poesia e prosa: uma reflexão sobre a cidade $e$ as suas arquitecturas, Coimbra, Faculdade de Ciências e Tecnologia da Universidade de Coimbra, Dezembro de 1998. Prova final1 da licenciatura em Arquitectura, policopiada.

RIBEIRo, António Lopes - "Diante dum jazigo", Diário de Coimbra, ano XIX, n. ${ }^{\circ}$ 5902, domingo, 26 de Setembro de 1948, pp. 1 e 5.

Ribeiro, António Lopes Ribeiro - "Demolições", Diário de Coimbra, ano XIX, n. ${ }^{\circ}$ 5874, domingo, 29 de Agosto de 1948, pp. 1 e 4.

Rosmaninho, Nuno - "A cidade universitária no Estado Novo: o espaço indisponível”, Monumentos, Lisboa, 8 (Março de 1998) p. 73-77.

Rosmaninho, Nuno - O poder da arte: o Estado Novo e a cidade universitária de Coimbra, Coimbra, Imprensa da Universidade, 2006. 
Rosmaninho, Nuno - O princípio de uma "revolução urbanística" no Estado Novo: os primeiros programas da Cidade Universitária de Coimbra (1934-1940), Coimbra, Minerva Editora, 1996.

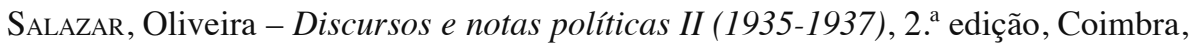
Coimbra Editora, 1945.

Seabra, Jorge [de]- "A nova cidade universitária de Coimbra", Estudos de Castelo Branco. Revista de história e cultura, Castelo Branco, 8 (1 de Abril de 1963) p. 109-112.

Seabra, Jorge de - "A Coimbra Académica do meu tempo: o escolar António Fragoso de Almeida", Rua Larga, Coimbra, 34 (15 de Dezembro de 1959) p. 441-444.

Seabra, Jorge de - "A Coimbra académica do meu tempo: o escolar Maximino Correia", Rua Larga, Coimbra, volume II, n. . 24, 6 de Abril de 1959, pp. 97-102.

Seabra, Jorge de - "Recordando a velha Coimbra académica: o Fulgêncio", Rua Larga, Coimbra, 23 (15 de Março de 1959) p. 76-77.

SeAbra, Jorge de - "Tipos da velha Coimbra: a madame Chardonay", Rua Larga, Coimbra, 28 (14 de Junho de 1959) p. 236-239.

Torgal, Luís Reis - A universidade e a academia de Coimbra perante o Estado Novo (1926-1961): entre a tradição e a inovação, separata da Revista de História, Porto, volume X, 1990, pp. 207-216.

Torgal, Luís Reis - A universidade e a classe dirigente durante o "Estado Novo" português, separata de Antonio Alvarez de Morales e Constantino García (recopiladores), Las Clases Dirigentes, Madrid, Editorial de la Universidad Complutense, 1992.

Torgal, Luís Reis - A universidade e o Estado Novo: o caso de Coimbra (1926-1960), Coimbra, Livraria Minerva, 1999.

Urbano, Abel - "Urbanização de Coimbra: a cidade universitária", O Despertar, Coimbra, ano XVIII, n. ${ }^{\circ}$ 1795, 1797, 1799. 1801, 1805 e 1807, 7, 14, 21 e 28 de Novembro e 12 e 19 de Dezembro de 1934, p. 1.

\section{Webgrafia}

https://mbasic.facebook.com/estudantesdecoimbra Acedido em 27 de Março de 2014. http://intergeras.wordpress.com Acedido em 27 de Março de 2014.

http://www.ruc.pt Acedido em 27 de Março de 2014.

http://opinadordeveludo.blogspot.pt Acedido em 27 de Março de 2014.

http://www.forumcoimbra.com Acedido em 27 de Março de 2014.

http://www.publico.pt Acedido em 27 de Março de 2014.

http://5dias.wordpress.com Acedido em 27 de Março de 2014.

http://aventar.eu Acedido em 27 de Março de 2014. 